\title{
EFEITO DE SUBDOSES DE GLYPHOSATE E 2,4-D SIMULANDO DERIVA NA CULTURA DE MAMONA
}

\author{
Murilo Villas Boas Bagatta ${ }^{1}$, Guilherme Sasso Ferreira de Souza ${ }^{2}$, Hermeson dos Santos \\ Vitorino $^{3}$, Maria Renata Rocha Pereira ${ }^{4}$, Dagoberto Martins ${ }^{5}$ \\ 1 Mestrando em Agronomia - Departamento de Produção Vegetal da ESALQ / USP Piracicaba (SP). \\ bagatto_@hotmail.com. \\ ${ }^{2}$ Doutorando em Agronomia - Departamento de Produção Vegetal da Faculdade de Ciências Agronômicas / \\ UNESP Botucatu (SP). \\ ${ }^{3}$ Professor Doutor da Universidade Estadual do Piauí Picos (PI). \\ ${ }^{4}$ Professora Doutora da FATEC de Capão Bonito (SP). \\ ${ }^{5}$ Professor Livre-Docente do Departamento de Produção Vegetal da Faculdade de Ciências Agrárias e \\ Veterinária / UNESP, Jaboticabal (SP).
}

RESUMO: A deriva de herbicidas como glyphosate e 2,4-D podem causar injúrias em plantações vizinhas à área aplicada. Assim, objetivou-se com este trabalho verificar a influência dos herbicidas glyphosate e 2,4-D no desenvolvimento das plantas de mamona (Ricinus communis). A cultivar de mamona utilizada foi a IAC-Guarani. Os tratamentos com subdoses, simulando deriva, foram: (i) 640,$0 ; 320,0 ; 160,0 ; 80,0 ; 40,0 ; 20,0 ; 10,0 ; 5,0 \mathrm{e}$ 2,5 g i.a. ha ${ }^{-1}$ de 2,4-D (DMA 806 BR) e (ii) 720,0; 360,0; 180,0; 90,0; 45,0; 22,50; 11,25; 5,63 e 2,81 g e.a. ha ${ }^{-1}$ de glyphosate (Round-up Original), além de uma testemunha sem aplicação de herbicida. Para a aplicação dos herbicidas utilizou-se um pulverizador costal pressurizado a $\mathrm{CO}_{2}$ equipado com pontas XR 11002 VS que proporcionam um volume de calda de pulverização de $200 \mathrm{~L} \mathrm{ha}^{-1}$. O delineamento experimental utilizado foi em blocos inteiramente casualizados com quatro repetições. Avaliaram-se os sintomas visuais de fitotoxicidade e a massa seca das plantas. Todas as doses testadas de ambos os herbicidas proporcionaram injurias visuais as plantas de mamona. Quanto ao acúmulo de massa seca, doses de glyphosate menores que 22,50 g e.a. ha ${ }^{-1}$ e de 2,4-D menores do que 20,0 g i.a. ha ${ }^{-1}$ proporcionaram acúmulo semelhante aos observados na testemunha, porém em termos porcentuais inferiores.

Palavras-chave: Ricinus communis. Herbicida. Fitotoxicidade.

\section{EFFECTS OF GLYPHOSATE AND 2,4-D SUBLETHAL RATES SIMULATING DRIFT ON CASTOR BEANS}

\begin{abstract}
The drift of herbicides as glyphosate and 2,4-D can cause injuries in the nearby fields applied areas. So, the aim with this study was to verify the influence of glyphosate and 2,4-D in the development of castor bean plants. The castor bean cultivar used was the IAC-Guarani. Treatments with sub-lethal doses, simulating drift, were: (i) 640.0, 320.0, 160.0, 80.0, 40.0, 20.0, 10.0, 5.0, and 2.5 g a.e. ha ${ }^{-1}$ 2,4-D (DMA 806 BR) and (ii) $720.0,360.0,180.0,90.0,45.0,22.50,11.25,5.63$ and $2.81 \mathrm{~g}$ a.i. $\mathrm{ha}^{-1}$ glyphosate (Round-up Original) and a control without herbicide. For the application of herbicides was
\end{abstract}

Cultura Agronômica, Ilha Solteira, v.24, n.3, p.361-370, 2015 
used a $\mathrm{CO}_{2}$ pressurized backpack sprayer equipped with XR 11002VS tips that provide a spray solution volume of $200 \mathrm{~L} \mathrm{ha}^{-1}$. The experimental design used was in blocks completely randomized with four replications. Were evaluated the visual symptoms of phytotoxicity and plant dry. All tested doses of both herbicides provided visual injuries at the castor bean plants. As for the dry mass, doses smaller than $22,5 \mathrm{~g}$ a.e. ha ${ }^{-1}$ of glyphosate and less than 20,0 $\mathrm{g}$ a.i. $\mathrm{ha}^{-1}$ of 2,4-D caused an accumulation similar to those observed in the control, but lower in percentage terms.

Key words: Ricinus communis. Herbicide. Phytotoxicity.

\section{INTRODUÇÃO}

A espécie Ricinus communis, popularmente conhecida como mamona ou carrapateiro, é uma planta oleaginosa da família Euphorbiacea de porte arbustivo. Devido a um grande número de variedades encontradas, tanto no continente africano como no asiático, tentativas de estabelecer a procedência efetiva da mamona são impossibilitadas. Trazida pelos portugueses para extração de seu óleo, adaptou-se muito bem ao clima tropical do Brasil e rapidamente se alastrou-se, assim, hoje pode-se encontrá-la em quase toda extensão territorial, como se fosse uma planta nativa (MATOS, 2007).

Com o crescente aumento no uso de herbicidas, seu emprego deve cercar-se de uma série de medidas, que vão desde os problemas relativos à deriva que podem atingir cultivos vizinhos e/ou alvos indesejáveis até intoxicações sofridas pelo homem e animais, além de conseqüências, muitas vezes, irreversíveis ao ambiente (AMARAL; PINTO, 1998). Estudos demonstram que pulverizações com ventos de $2 \mathrm{~m} \mathrm{~s}^{-1}$, a deriva de glyphosate pode atingir até $160 \mathrm{~m}$ e a de sulfosate pode atingir até $200 \mathrm{~m}$ além do local considerado alvo (SCHRODER et al., 2000). A ocorrência de deriva deve-se principalmente pelas condições climáticas e tamanho das gotas pulverizadas. Fato este que resulta em gastos desnecessários devido à redução da eficácia dos herbicidas no controle das plantas daninhas, que pode ser contornado com o aumento compensatório da dosagem (HEMPHILL JUNIOR; MONTGOMERY, 1981).

Existem vários relatos de injúrias causadas em diversas culturas por deriva de 2,4-D. Um estudo de deriva simulada dos herbicidas dicamba, 2,4-D e picloram foi realizado sobre a cultura de beterraba (Beta vulgaris L.) em diversos estádios de desenvolvimento por Schroeder, et al. (1983), no qual se verificou efeitos visuais de fitotoxidade que foram correlacionados com a redução do rendimento e da qualidade dos produtos colhidos. A aplicação de subdoses de herbicidas, simulando deriva, também foi utilizada por Eberlein e Guttieri (1994), tendo como objetivo verificar a resposta da cultura da batata (Solanum tuberosum L.) a aplicação de subdoses de imazamethabenz, imazethapyr e imazapyr (2, 10 e $50 \%$ das doses recomendadas para cada herbicida). As pesquisadoras verificaram que os sintomas de fitotoxicidade nas folhas variam com a molécula do herbicida, a dose aplicada, o estádio de desenvolvimento e o momento da pulverização. Já a aplicação de MSMA em algodão, com deriva na cultura de arroz (Oryza sativa L.), causou redução na altura das 
plantas, no número de panículas e na produção de grãos (RICHARD et al., 1981).

O herbicida 2,4-D é utilizado em áreas com predominância de dicotiledôneas, sendo sua absorção realizada pelo caule, raiz e folhas (CHRISTOFFOLETI et al., 2004). Seu mecanismo de ação envolve os sistemas enzimáticos carboximetil celulase e RNA polimerase. Estes sistemas são respectivamente responsáveis pela plasticidade da membrana celular e pelo metabolismo de ácidos nucléicos. Como resultado, ocorre aumento anormal de DNA, RNA e proteínas que promovem a divisão descontrolada das células e o crescimento anormal das plantas sensíveis. Os sintomas mais evidentes são epinastia foliar, enrolamento e curvamento de ramos e caule e, paralisação do crescimento seguido de necrose e clorose meristemática. A morte pode ocorrer após cinco semanas de aplicação (VARGAS, 2003). Já o glyphosate é um herbicida não-seletivo, de ação sistêmica, usado no controle de plantas daninhas anuais e perenes e, aparentemente, tem pouca atividade residual no solo (RODRIGUES; ALMEIDA, 1998). Sua formulação ([Nfosfonometil]glicina) quando absorvida pela planta bloqueia a biossíntese de aminoácidos aromáticos, inibindo a atividade da 5-enol-piruvil-chiquimato-3-fosfato sintase - EPSPS (KISHORE et al., 1992). Sua eficácia se dá tanto em dicotiledôneas como em monocotiledôneas (ZAGONEL; MAROCHI, 2000).

Objetivou-se com este trabalho verificar a influência dos herbicidas glyphosate e 2,4D no desenvolvimento das plantas de mamona.

\section{MATERIAL E MÉTODOS}

O estudo foi conduzido em casa de vegetação, durante o ano de 2010, no Núcleo de Pesquisa Avançadas em Matologia (NuPAM) que pertence ao Departamento de Produção Vegetal da FCA/UNESP, Botucatu/SP. O solo utilizado foi retirado da gleba denominada patrulha da própria faculdade e é classificado como Latossolo Vermelho-Escuro distrófico, textura média $\left(\mathrm{Le}_{\mathrm{d}}\right)$.

O delineamento experimental utilizado foi em blocos inteiramente casualizados com quatro repetições. Utilizaram-se cinco sementes de mamona para semeadura da cultivar IAC-Guarani em vasos de 8,0 L e logo após a emergência foi realizado um desbaste deixando apenas uma planta.

Foram testados dois herbicidas, 2,4-D e glyphosate e, nove doses para ambos os produtos: (i) 2,4-D (DMA 806 BR) a 640,0; 320,0; 160,0; 80,0; 40,0; 20,0; 10,0; 5,0 e 2,5 g i.a ha ${ }^{-1}$ e, (ii) glyphosate (Round-up Original) a 720,0;360,0;180,0; 90,0;45,0; 22,50; 11,$25 ; 5,63$ e 2,81 g e.a ha-1 ${ }^{-1}$ além de uma testemunha sem aplicação de herbicida.

A aplicação dos herbicidas foi realizada com um pulverizador costal pressurizado a $\mathrm{CO}_{2}$ equipado com um reservatório de 2 litros e regulado para proporcionar um volume de calda de 200L ha ${ }^{-1}$. A barra de aplicação estava equipada com quatro pontas do tipo jato plano "Teejet" XR 11002 VS, distanciados $50 \mathrm{~cm}$ entre si. A pulverização foi realizada diretamente sobre as plantas de mamona quando elas estavam com $50 \mathrm{~cm}$ de altura, mantendo a barra $0,3 \mathrm{~m}$ a cima do topo das plantas.

Cultura Agronômica, Ilha Solteira, v.24, n.3, p.361-370, 2015 
Os efeitos da simulação de deriva dos herbicidas 2,4-D e glyphosate foram avaliados através das seguintes variáveis:

Fitotoxicidade - As avaliações visuais dos efeitos de fitotoxicidade causados às plantas de mamona foram efetuadas aos 7, 14, 21 e 28 dias após a aplicação (DAA). Os danos foram quantificados com o auxílio de escala percentual, utilizando valores entre zero (0) e cem (100), que representaram, respectivamente, nenhuma injúria e morte das plantas (SBCPD, 1995).

Massa seca - Após 28 dias da aplicação dos tratamentos, foi colhida a parte aérea da planta de mamona, sendo colocadas em estufa de circulação forçada de ar, a uma temperatura média de $60^{\circ} \mathrm{C}$, até atingir massa constante. Após essa etapa efetuou-se a pesagem do material, para essa análise qualitativa, utilizou-se balança digital com capela e precisão de quatro casas decimais.

Os dados foram submetidos à análise variância pelo teste $\mathrm{F}$ e as médias dos tratamentos foram comparadas pelo teste de Tukey a 5\%.

\section{RESULTADOS E DISCUSSÃO}

Na Tabela 1 observa-se que as injúrias provocadas pelo herbicida glyphosate já foram severas a partir da primeira avaliação visual feita aos sete dias após sua aplicação (DAA), sendo esta elevada desde a aplicação da dose de 11,25 g e.a. ha ${ }^{-1}$. Ressalta-se que as duas maiores doses testadas (360 e 720 g e.a. ha-1) proporcionaram as maiores porcentagens de injúrias às plantas de mamona, o que as levou a morte aos 21 DAA do herbicida.

Aos 14 DAA todas as doses avaliadas proporcionaram um incremento acentuado na fitotoxicidade observada, exceto as quatro menores doses estudadas. Registra-se aos 21 DAA, um novo aumento nos sintomas de injúrias provocados pelas doses de 45,90 e 180,00 g e.a. ha ${ }^{-1}$ de glyphosate, que evoluíram até aos 28 DAA. Quanto à dose de 22,50 g e.a. ha-1, verifica-se que esta apresentou um comportamento semelhante em todas as avaliações realizadas, pois as plantas de mamona demonstraram sintomas de injúrias entre 23 e $24 \%$ de fitotoxicidade.

As plantas que receberam as doses de $11,25,5,63$ e 2,81 g e.a. ha ${ }^{-1}$ registraram danos que oscilaram muito dependendo da avaliação observada. Contudo, o percentual mais alto foi de $19 \%$ aos 14 DAA, o que demonstra injúrias leves causados por baixas doses. Esta oscilação foi decorrente da presença de sintomas nas folhas antigas, sendo que os brotos novos foram emitidos de forma sadia.

As doses altas rapidamente apresentaram intensa clorose do limbo foliar, que pode ser notado já na primeira avaliação (7 DAA). Durante todas as avaliações as três menores doses foram classificadas com sintomas de fitointoxicação leve ou moderada. Houve ainda uma sensível evolução dos sintomas no decorrer das avaliações e, logo em seguida, posterior redução com a provável metabolização da molécula herbicida.

Cultura Agronômica, Ilha Solteira, v.24, n.3, p.361-370, 2015 
SILVA et al. (2008), objetivando avaliar os efeitos das diferentes doses do herbicida glyphosate $\left(200 ; 400 ; 600 ; 1000 ; 1200 ; 1400 ; 1600 ; 1800\right.$ e $2000 \mathrm{~g} \mathrm{e.a} \mathrm{ha}^{-1}$ ), relataram como principais sintomas de fitotoxicidade do produto sobre a mamoneira necrose e amarelecimento das folhas. Os autores também relataram efeitos fitotóxicos sobre a cultura a partir da menor dose utilizada no trabalho (200 g e.a ha $\mathrm{ha}^{-1}$ ), sendo que na primeira avaliação aos 7 DAA todos os tratamentos receberam nota 5 de acordo com a tabela EWRC (1964). Já aos 14 DAA a sintomatologia evoluiu de forma significativa resultando em severa fitointoxicação das plantas em relação aos demais tratamentos e à testemunha sem herbicida, caracterizado principalmente por necrose em todas as plantas. Estas plantas de mamoneira receberam de acordo com a escala EWRC nota 9. Em outro estudo Alexandria Junior et al. (2011), testando subdoses de glyphosate $(0 ; 100 ; 200 ; 300$ e 400 g e.a. ha-1) observaram que a cultivar BRS Energia também apresentou sintomas de fitointoxicação a partir da dose de $200 \mathrm{~g}$ e.a. $\mathrm{ha}^{-1}$. Dados distintos foram observados no presente trabalho, no qual maiores níveis de fitointoxicação sobre a cultura da mamoneira foram observados a partir da dose de $45 \mathrm{~g}$ e.a ha $^{-1}$, logo as menores doses resultaram em fotointoxicação de menor intensidade, essa disparidade pode ser justificada pela alta sensibilidade ao glyphosate da cultivar utilizada (IAC-Guarani).

Tabela 1. Porcentagem de fitotoxicidade promovida pelo herbicida glyphosate às plantas de mamona em diferentes períodos de avaliações. Botucatu / SP, 2010.

\begin{tabular}{lccccc}
\hline \multirow{2}{*}{ TRATAMENTOS } & Doses & \multicolumn{4}{c}{ Fitotoxicidade } \\
\cline { 3 - 6 } & $\left(\mathbf{g ~ e . a . ~ h a}^{-1}\right)$ & 7 DAA & 14 DAA & 21 DAA & 28DAA \\
\hline 1. glyphosate & 720,00 & $71,00 \mathbf{a}$ & $99,67 \mathbf{a}$ & $100,00 \mathbf{a}$ & $100,00 \mathbf{a}$ \\
2. glyphosate & 360,00 & $68,00 \mathbf{a b}$ & $99,67 \mathbf{a}$ & $100,00 \mathbf{a}$ & $100,00 \mathbf{a}$ \\
3. glyphosate & 180,00 & $41,00 \mathbf{c}$ & $86,00 \mathbf{a}$ & $97,00 \mathbf{a b}$ & $99,00 \mathbf{a b}$ \\
4. glyphosate & 90,00 & $44,33 \mathbf{b c}$ & $91,67 \mathbf{a}$ & $95,67 \mathbf{a b}$ & $98,00 \mathbf{a b}$ \\
5. glyphosate & 45,00 & $28,33 \mathbf{c d}$ & $48,33 \mathbf{b}$ & $83,33 \mathbf{b}$ & $77,33 \mathbf{b}$ \\
6. glyphosate & 22,50 & $23,33 \mathbf{c d}$ & $23,00 \mathbf{b c}$ & $23,00 \mathbf{c}$ & $24,33 \mathbf{c}$ \\
7. glyphosate & 11,25 & $18,00 \mathbf{c d}$ & $19,00 \mathbf{c}$ & $10,67 \mathbf{c d}$ & $12,67 \mathbf{c}$ \\
8. glyphosate & 5,63 & $5,33 \mathbf{d}$ & $2,00 \mathbf{c}$ & $8,67 \mathbf{c d}$ & $10,00 \mathbf{c}$ \\
9. glyphosate & 2,81 & $2,00 \mathbf{d}$ & $2,00 \mathbf{c}$ & $5,33 \mathbf{d}$ & $15,67 \mathbf{c}$ \\
\hline FTratamento & & $22,50 * *$ & $68,66 * *$ & $191,20 * *$ & $96,87 * *$ \\
Fbloco & & $0,701^{\text {ns }}$ & $0,401^{\mathbf{n s}}$ & $1,6177^{\text {ns }}$ & $0,834^{\mathbf{n s}}$ \\
C.V.(\%) & & 27,1 & 17,0 & 9,5 & 21,7 \\
\hline D.M.S. & & 26,38 & 25,78 & 16,16 & 21,76 \\
\hline
\end{tabular}

Médias seguidas de mesma letra na coluna não diferem estatisticamente entre si pelo teste de Tukey ( $\mathrm{p} \geqq 0,05)$. DAA - Dias Após Aplicação.

O efeito da deriva de glyphosate sobre o acúmulo de massa seca das plantas de mamona encontra-se apresentado na Figura 1. As plantas de mamona que receberam as cinco maiores doses de glyphosate $\left(720,00,360,00,180,00,90,00\right.$ e 45 g e.a. ha $\left.{ }^{-1}\right)$ apresentaram as maiores porcentagens de fitotoxicidade e por consequência, a massa seca 
acumulada pelas plantas foi pequena, havendo uma perda em média de $87 \%$ de massa em relação à testemunha.

As demais doses testadas, 22,50; 11,25; 5,63 e 2,81 g e.a. ha ${ }^{-1}$ proporcionaram acúmulo de massa seca nas plantas de mamona de forma semelhante à testemunha, porém em termos porcentuais, estes foram reduzidos e variou de 20,4 a $25,4 \%$, dependendo da dose estudada, com exceção à dose de 11,25 g e.a. ha ${ }^{-1}$.

Alexandria Junior et al. (2011) em aplicação de sub doses do herbicida glyphosato sobre a cultivar de mamona BRS Energia, observaram redução no acúmulo de massa seca nas doses de 300 e 400 g e.a. ha ${ }^{-1}$. Esta distinção dos dados pode ser justificada pela maior suscetibilidade ao herbicida glyphosate pela cultivar IAC-Guarani, resultando em menor acúmulo de massa seca mesmo em menores doses do herbicida.

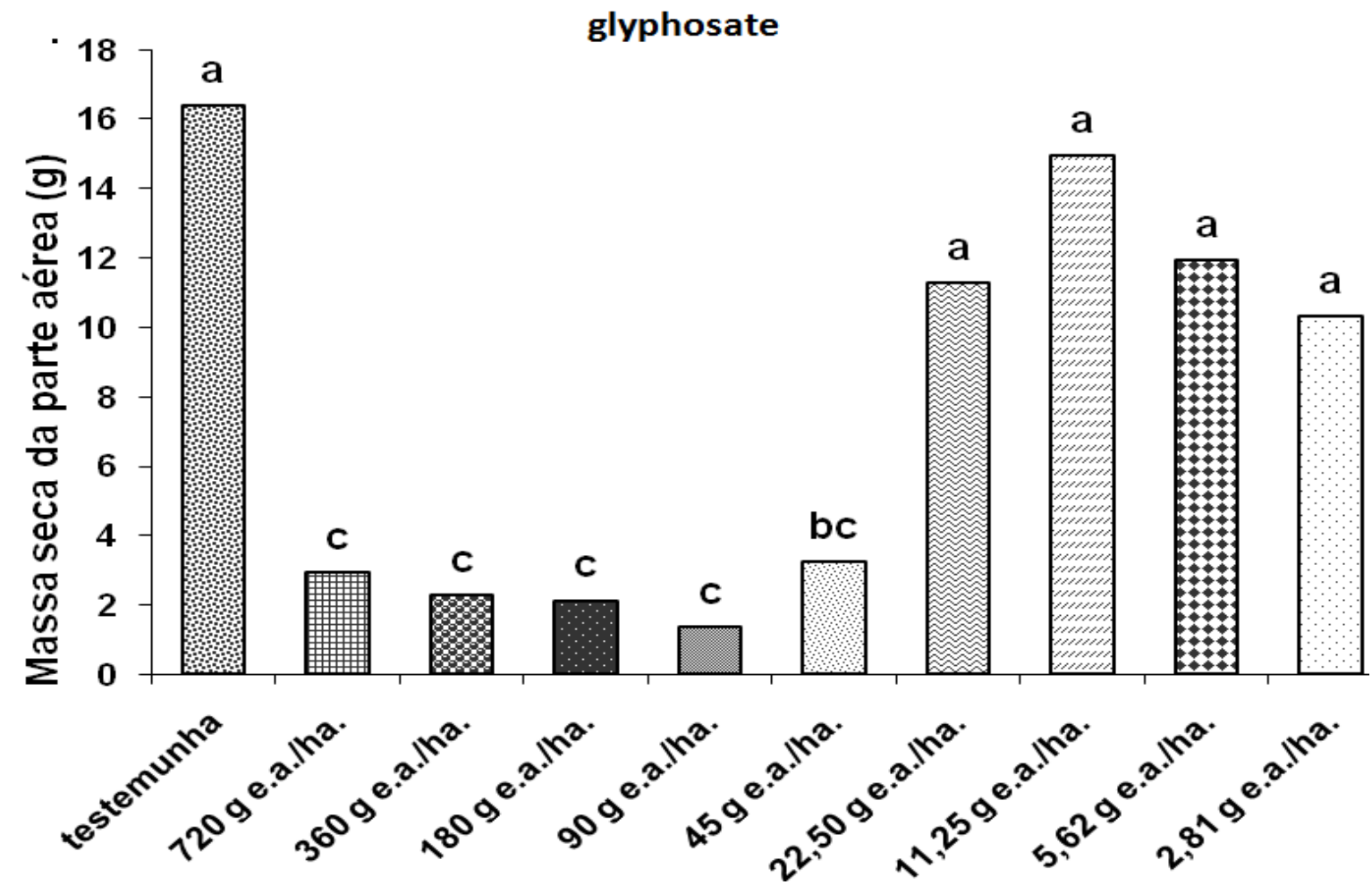

Figura 1. Efeito de doses de glyphosate sob o acúmulo de massa seca da parte aérea de plantas de mamona. Botucatu / SP, 2010.

$\mathrm{Na}$ Tabela 2 estão apresentadas às notas de fitointoxicação da cultura de mamona com aplicação de 2,4-D. A cultura da mamona mostrou-se muito sensível ao 2,4-D. Isso porque danos causados pelo herbicida 2,4-D foram severos desde a primeira avaliação aos 7 DAA, sendo estas elevadas a partir da dose de 40,00 g i.a.ha ${ }^{-1}$. Foi registrado que as plantas de mamona apresentaram da sua dose cheia $\left(640,00 \mathrm{~g}\right.$ i.a. ha $\left.{ }^{-1}\right)$ até a décima sexta parte desta (40,00 g i.a. ha $\left.{ }^{-1}\right)$ letalidade aos 28 dias após a aplicação. Nota-se que retirada algumas diferenças de injúrias nos primeiros catorze dias, na qual doses mais altas apresentaram sintomas mais rápido, as cinco maiores doses $\left(640,00\right.$ à 40,00 g i.a. ha $\left.{ }^{-1}\right)$ evoluíram de forma semelhante. A intensidade desses sintomas e o número de folhas afetadas cresceram com o aumento da dose do herbicida.

Cultura Agronômica, Ilha Solteira, v.24, n.3, p.361-370, 2015 
Ressalta-se que as plantas que receberam a dose de 20,00 g i.a. ha ${ }^{-1}$ registraram gradativo aumento de fitotoxidade. Apesar de não ter sido letal, ocasionou sintomas de $81,67 \%$ aos 28 DAA. Os tratamentos com as doses de 10,00 e 5,00 g i.a. ha ${ }^{-1}$ causaram injúrias leves aos 21 DAA e que aos 28 DAA essas duas doses proporcionaram um aumento significativo nos sintomas, sendo que a dose de 5,00 g i.a. ha ${ }^{-1}$ registrou 42,6\% de acréscimo de danos em relação a sua avaliação aos 21 DAA. Já a menor dose testada (2,50 g i.a. ha $\left.{ }^{-1}\right)$ causou a menor evolução de sintomas, registrando aos 28 DAA injúrias leves $(15,67 \%)$

As respostas de espécies de plantas à aplicação de subdoses de 2,4-D podem variar desde a completa seletividade até a elevada suscetibilidade. A cultura da canola, por exemplo, pode ser considerada sensível, uma vez que há redução na produtividade mesmo quando a cultura é exposta à aplicação de dose equivalente a apenas $1,5 \%$ da comercialmente utilizada (WALL, 1996). A dose de 1,5\% da comercial equivalente para mamona seria aproximadamente $10 \mathrm{~g}$ i.a. ha $^{-1}$. Nessa quantidade o herbicida 2,4-D causou fitoxidade de $39 \%$, o que provavelmente levaria a uma redução de sua produção. De forma oposta, Schoroeder et al. (1983) avaliaram a deriva simulada do herbicida 2,4-D sobre a cultura da beterraba (Beta vulgaris L.), em diferentes estádios de desenvolvimento da cultura, aplicando doses equivalentes a 35; 140 e 280 g i.a ha ${ }^{-1}$. A dose de 35 g i.a. ha ${ }^{-1}$, independentemente do estádio de aplicação, não afetou a produtividade, a pureza e o teor de sacarose da cultura, quando comparado com a testemunha.

Tabela 2. Notas visuais de subdoses do herbicida 2,4-D na cultura da mamona em diferentes períodos de avaliação. Botucatu/SP, 2010

\begin{tabular}{|c|c|c|c|c|c|}
\hline \multirow{2}{*}{ Tratamentos } & \multirow{2}{*}{$\begin{array}{c}\text { Doses } \\
\left(\text { g e.a. ha- } \text { ha }^{-1}\right)\end{array}$} & \multicolumn{4}{|c|}{ Fitotoxicidade } \\
\hline & & $7 \mathbf{D A A}$ & 14 DAA & 21 DAA & 28 DAA \\
\hline 1. 2,4-D & 640,0 & $73,33 \mathbf{a}$ & $100,00 \mathbf{a}$ & $100,00 \mathbf{a}$ & $100,00 \mathbf{a}$ \\
\hline 2. 2,4-D & 320,0 & $71,33 \mathbf{a}$ & $99,00 \mathbf{a}$ & $100,00 \mathbf{a}$ & $100,00 \mathbf{a}$ \\
\hline 3. 2,4-D & 160,0 & $69,00 \mathbf{a}$ & $98,67 \mathbf{a}$ & $100,00 \mathbf{a}$ & $100,00 \mathbf{a}$ \\
\hline 4. 2,4-D & 80,0 & $65,00 \mathbf{a}$ & $98,33 \mathbf{a}$ & $100,00 \mathbf{a}$ & $100,00 \mathbf{a}$ \\
\hline 5. 2,4-D & 40,0 & $44,33 \mathbf{b}$ & $89,33 \mathbf{a}$ & $99,00 \mathbf{a}$ & $100,00 \mathbf{a}$ \\
\hline 6. 2,4-D & 20,0 & $26,00 \mathbf{c}$ & $53,33 \mathbf{b}$ & $77,00 \mathbf{a}$ & $81,67 \mathbf{a b}$ \\
\hline 7. 2,4-D & 10,0 & $8,00 \mathbf{d}$ & $11,67 \mathrm{c}$ & $11,67 \mathbf{b}$ & $39,33 \mathbf{b c}$ \\
\hline 8. 2,4-D & 5,0 & $0,00 \mathbf{d}$ & $3,00 \mathbf{c}$ & $4,00 \mathbf{b}$ & $46,67 \mathbf{b c}$ \\
\hline 9. 2,4-D & 2,5 & $0,00 \mathbf{d}$ & $3,00 \mathrm{c}$ & $9,00 \mathbf{b}$ & $15,67 \mathrm{c}$ \\
\hline F Tratamento $_{\text {T }}$ & & $162,46 * *$ & $166,22 * *$ & $39,39 * *$ & $9,84 * *$ \\
\hline$F_{\text {bloco }}$ & & $1,643^{\mathrm{ns}}$ & $0,578^{\mathrm{ns}}$ & $1,915^{\mathrm{ns}}$ & $1,726^{\mathrm{ns}}$ \\
\hline C.V.(\%) & & 10,8 & 9,6 & 18,4 & 24,1 \\
\hline D.M.S. & & 12,48 & 17,34 & 35,71 & 53,06 \\
\hline
\end{tabular}

Médias seguidas de mesma letra não diferem estatisticamente entre si pelo teste de Tukey $(p \geqq 0,05)$. DAA Dias Após Aplicação.

$\mathrm{O}$ efeito da deriva de 2,4-D sobre o acúmulo de massa seca das plantas de mamona encontra-se apresentado na Figura 2. As plantas de mamona que receberam as cinco maiores doses de 2,4-D (640,00; 320,00; 160,00; 80,00 e 40,00 g i.a. ha $\left.{ }^{-1}\right)$ registraram as maiores

Cultura Agronômica, Ilha Solteira, v.24, n.3, p.361-370, 2015 
porcentagens de fitotocixidade e por consequência, houve uma perda em média de $80 \%$ de massa em relação à testemunha.

As demais doses estudadas 20,00, 10,00, 5,00 e 2,50 g i.a. ha ${ }^{-1}$ proporcionaram um acúmulo de massa seca que aumentou com decréscimo da dose, sendo a diferença de massa da testemunha em relação à dose de 2,50 g i.a. ha- ${ }^{-1}$ foi de $5,3 \%$.

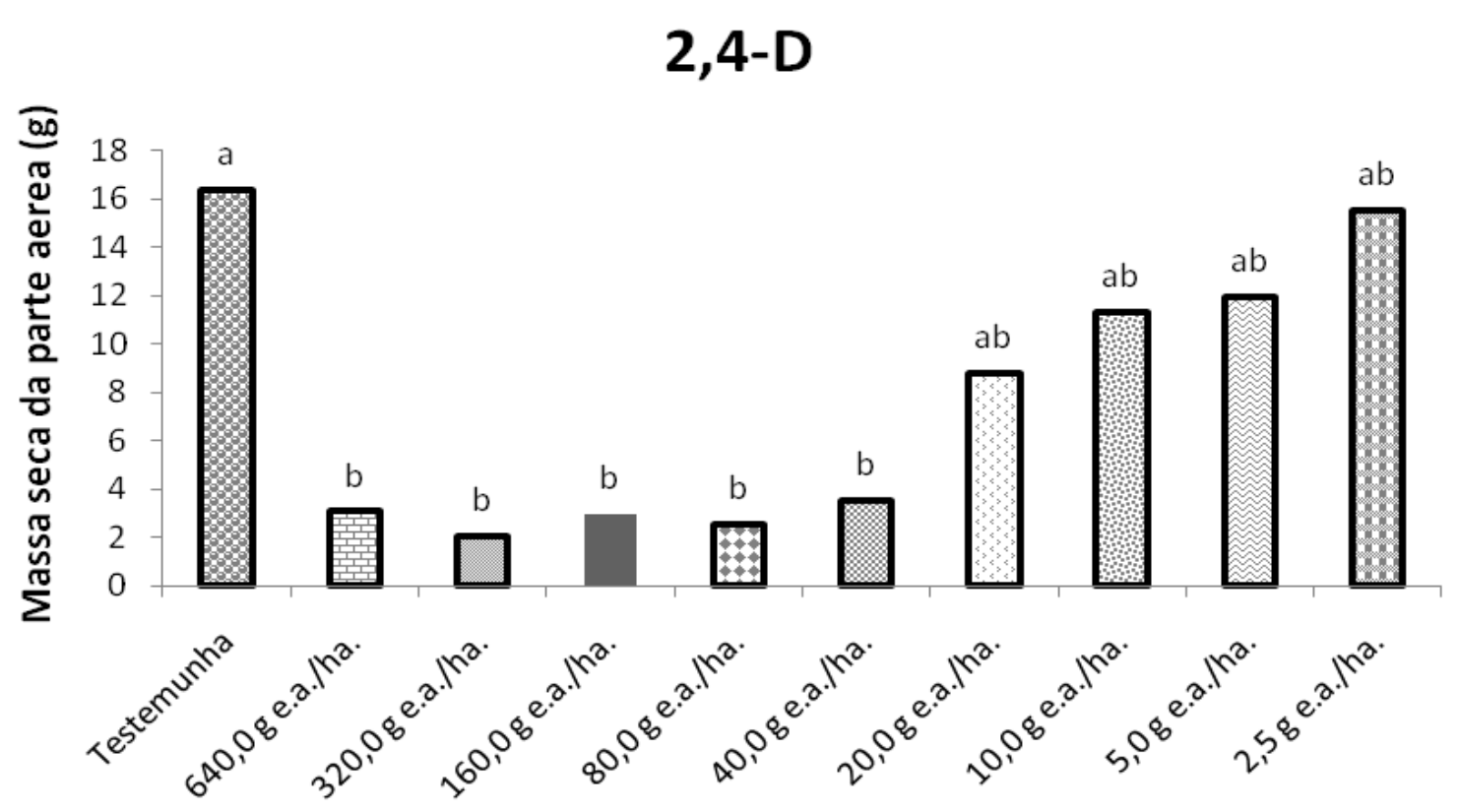

Figura 2. Efeito de doses de 2,4-D sob o acúmulo de massa seca da parte aérea de plantas de mamona. Botucatu / SP, 2010.

\section{CONCLUSÃO}

Todas as doses testadas de glyphosate e 2,4-D causaram injúrias crescentes conforme o aumento da dose. Em relação à massa seca, as plantas pulverizadas com doses acima de 45,0 g e.a. ha ${ }^{-1}$ de glyphosate acumularam aproximadamente 6 vezes menos matéria seca, enquanto doses menores que $22,5 \mathrm{~g}$ e.a. $\mathrm{ha}^{-1}$ foram semelhantes a testemunha. Já as plantas aplicadas com doses maiores que 40,0 g i.a. ha ${ }^{-1}$ de 2,4-D tiveram uma redução no acúmulo de aproximadamente 5 vezes menos matéria seca, e doses menores que 20,0 g i.a. ha ${ }^{-1}$ de 2,4-D foram semelhantes a testemunha.

\section{REFERÊNCIAS BIBLIOGRÁFICAS}

ALEXANDRIA JÚNIOR, F. F.; ARAÚJO, W. P.; LEITE, A. G.; ARAÚJO, V. L.; LIMA, F. V.; PEREIRA, J. R. Fitotoxicidade do herbicida glifosato em infradoses na mamoneira (Ricinus communis L.) cultivar BRS ENERGIA. Educação Agrícola Superior, Brasília, v. 26, n. 1, p.30-35, 2011.

Cultura Agronômica, Ilha Solteira, v.24, n.3, p.361-370, 2015 
AMARAL, A. S.; PINTO, J. J. O. Controle de plantas daninhas. In: PESKE, S.T. (Ed.) Produção de arroz. 1 ed. Pelotas: Editora e Gráfica Universitária - UFPel, 1998. p. 209276.

CHRISTOFFOLETI, P. J.; OVEJERO, R. F. L.; CARVALHO, J. C. Aspectos de resistência de plantas daninhas a herbicidas. Campinas: HARC-BR, 2004. 100 p.

EBERLEIN, C. V.; GUTTIERI, M. J. Potato (Potato tuberosum) response to simulate drift of imidazoline herbicides. Weed Science, Champaign, v. 42, n. 1, p.70-75, 1994.

EWRC. Report of 3rd and 4th meetings of - committee of methods in weed research. Weed Research, Oxford, v. 4, n. 1, p. 88, 1964.

HEMPHILL JUNIOR, D. D.; MONTGOMERY, M. L. Response of vegetable crops to sublethal application of 2,4-D. Weed Science, Champaign, v. 29, n. 6, p.632-635, 1981.

KISHORE, G. M.; PADGETTE, S. R.; FRALEY, R. T. History of herbicide-tolerant crops, methods of development and current state of the art-emphasis on glyphosate tolerance. Weed Technology, Lawrence, v. 6, p.626-634, 1992.

MATOS, H. S. F. M. Dossiê técnico: cultivo da mamona e extração de óleo. Brasília: CDT / UnB, 2007. 29 p. Disponível em: <http://www.sbrt.ibict.br/dossietecnico/downloadsDT/MjE3>. Acesso em: 3 set. 2011.

RICHARD JÚNIOR., E. P.; HURST, H. R.; WAUCHOPE, R. D. Effects of simulated MSMA drift on rice (Oriza sativa) growth and yield. Weed Science, Champaign, v. 29, n. 3, p.303-308, 1981.

RODRIGUES, B. N.; ALMEIDA, F. S. Guia de herbicidas. Londrina: IAPAR, 1998. 648 p.

SCHOROEDER, G. L.; COLE, D. F.; DEXTER, A. G. Sugarbeet (Beta vulgaris L.) response to simulated herbicide spray drift. Weed Science, Champaign, v. 31, n. 6, p.831836, 1983.

SCHRODER, E. P.; PINTO, J. J. O.; SILVA, J. B. Avaliação de pulverizações aéreas dos herbicidas sulfosate e glyphosate. In: CONGRESSO BRASILEIRO DA CIÊNCIA DAS PLANTAS DANINHAS, 22., 2000, Foz do Iguaçu. Resumos.... Foz do Iguaçu: Sociedade Brasileira da Ciência das Plantas daninhas, 2000. p. 478.

SILVA, W. A.; ARAÚJO JUNIOR, F. F.; OLIVEIRA, M. I. P.; NEVES, F. T. F.; DANTAS, J. P.; BELTRÃO, N. E. M. Fitotoxidade da mamoneira em resposta a diferentes

Cultura Agronômica, Ilha Solteira, v.24, n.3, p.361-370, 2015 
doses do herbicida glifosato. In: CONGRESSO BRASILEIRO DE MAMONA, 3., 2008, Salvador. Anais... Salvador, 2008. CD-ROOM.

SOCIEDADE BRASILEIRA DA CIÊNCIA DAS PLANTAS DANINHAS - SBCPD. Procedimentos para instalação, avaliação e análise de experimentos com herbicidas. Londrina: SBCPD, 1995. 42 p.

VARGAS, L. Sintomas e diagnose de toxicidade herbicida na cultura da maçã. Bento Gonçalves: EMBRAPA, 2003. 9 p. (Circular Técnica, 44)

WALL, D. A. Effect of sublethal dosages of 2,4-D on annual broadleaf crops. Canadian Journal of Plant Science, Ottawa, v. 76, n. 1, p.179-85, 1996.

ZAGONEL, J.; MAROCHI, A. I. Eficiência e seletividade do glifosato em soja Roundup Ready em diferentes épocas no controle de plantas daninhas. In: CONGRESSO BRASILEIRO DA CIÊNCIA DAS PLANTAS DANINHAS, 22., 2000, Foz do Iguaçu. Resumos.... Londrina: SBCPD, 2000. p. 180. 